Cadernos de Clio, Curitiba, n. ${ }^{\circ} 2,2011$

\title{
Alexandre da Macedônia: cunhagens com aspecto de propaganda
}

Estela de Melo Faria ${ }^{1}$

Resumo: Quando as imagens são o objeto de estudo, uma gama de opções e interpretações se abre a nossa frente. A moeda como documento pode informar sobre os mais variados aspectos de uma sociedade. Tanto político e estatal, quanto jurídico e religioso. Alexandre tornou-se rei aos 20 anos, governando de 336 a.C. a 326 a.C.. Apesar de ter um curto reinado, foi um general de extraordinária habilidade: conquistou um império que ia dos Bálcãs à Índia, incluindo também o Egito e a Bactria (aproximadamente o atual Afeganistão). As moedas não apenas são instrumentos importantes para estabelecer a datação de documentos e eventos que chegaram até nós sem seu contexto original, como são de grande valia na nossa compreensão das imagens que contêm.

Palavras-chave: Moedas, Alexandre, propaganda.

\section{Introdução}

Muitas vezes o que é desconhecido nos chama a atenção, pelo simples motivo de podermos tornar claros vários temas ainda "obscuros" no cenário que estudamos. O homem, durante a sua passagem pelo planeta, desenvolveu diversas formas simbólicas, tanto artísticas quanto linguísticas, expressas por sua consciência.

\footnotetext{
${ }^{1}$ Graduanda em História da Universidade Federal de Alfenas sob orientação do Prof. Dr. Cláudio Umpierre Carlan.
} 
Quando as imagens são o objeto de estudo, uma gama de opções e interpretações se abre a nossa frente. A moeda como documento pode informar sobre os mais variados aspectos de uma sociedade. Tanto políticos e estatais, quanto jurídicos e religiosos.

Em sociedades em que poucos sabiam ler e escrever, as imagens eram de extrema importância para que a população soubesse dos acontecimentos e conquistas de seus governantes. Muitos chefes estatais utilizaram esse artifício para tornar públicas suas conquistas. Alexandre III vulgo, o Grande, foi um desses chefes que empregaram esse meio, e é em suas moedas que os estudos desse projeto se concentrarão.

As cunhagens de Alexandre Magno se inserem nesse contexto do desconhecido, pouco ou quase nada foram estudadas no cenário nacional. O objetivo do projeto de pesquisa, que se encontra em seu inicio, seria catalogá-las.

Elas são dracmas (moedas gregas utilizadas na época) de prata, num conjunto de aproximadamente 35 peças, encontradas no Museu Histórico Nacional (MHN) no Rio de Janeiro, e constituem o maior acervo numismático da América Latina.

Como esta pesquisa está em seu inicio, as hipóteses aqui construídas podem ser refutadas, ou ter sua veracidade comprovada. 


\section{O Governo de Alexandre}

Alexandre, o Grande, nascido no ano 356 a.C. e falecido no ano 323 a.C., filho de Filipe II e Olímpia, descendia, segundo Plutarco, de Hércules, pelo lado paterno, e dos Eaclides, pelo lado materno.

Desde pequeno ambicionava a fama de um homem eloqüente. Assumiu o reino aos 20 anos quando seu pai foi assassinado e se preocupou em castigar severamente os envolvidos no crime. Alexandre foi um grande general e o mais célebre conquistador do mundo antigo. Apesar de seu curto reinado, conquistou um império que ia dos Balcãs à Índia, incluindo também o Egito e a Bactria (atual Afeganistão), sendo esta a máxima extensão do império.

É considerado um homem de visão, extremamente inteligente, que tentou criar uma síntese entre o Ocidente e o Oriente, estimulando o casamento de seus soldados com mulheres persas. Ele mesmo casou-se com uma princesa bactriana.

Respeitava seus inimigos. Era um grande admirador das

ciências e das artes: um bom exemplo que pode ser tomado é a célebre Alexandria, o maior centro cultural, científico e econômico da antiguidade, até a ascensão do Império Romano. 
Cadernos de Clio, Curitiba, n. ${ }^{\circ} 2,2011$

Acometido por uma febre e padecendo de uma profunda alteração, morreu prematuramente aos 30 do mês de desius (maio/junho), sendo que ninguém suspeitou de envenenamento.

\section{Trabalho com imagens}

Muitos autores contemporâneos chegam perto do tema aqui sugerido. Por exemplo, Pedro Paulo Abreu Funari ${ }^{2}$,que em seu livro Grécia e Roma vida pública e vida privada, cultura, pensamento e mitologia, amor e sexualidade nos mostra como a moeda tem um papel importante nas sociedades antigas:

“... levou os gregos e a civilização grega a lugares longínquos. A Grécia propriamente dita viu prosperar enormemente o desenvolvimento do comércio marítimo e do artesanato (produção de armas e cerâmica). Foi introduzido o uso da moeda, algo muito importante tanto no sentido comercial, de facilitar as trocas, como no político, já que passaram a ser emitidas pelas cidades- estados." (grifo meu) (FUNARI: 2002, 26).

Entre outros exemplos, podem-se citar entre os
pesquisadores nacionais Maria Beatriz B. Florenzano (USP, Numismática e História Antiga), André Chevitarese (UFRJ, Professor dos cursos de Mestrado e Doutorado da UNICAMP,

${ }^{2}$ Professor titular de História Antiga, UNICAMP. 
Amuletos, Salomão e Cultura Helenística), o Laboratório de História Antiga da UFRJ (fundado por Neyde Telm), Maria Regina Candido, da UERJ, que estuda a imagem na Grécia Antiga, Fábio Vergara Cerqueira (UFPEL, trabalha com a musica na Grécia Antiga, voltado ao estudo de várias temáticas do cotidiano, tese de doutorado na USP), Haiganuch Sarian (USP, Professora e orientadoras dos demais autores, artigo SARIAN: 2001 v. 13/14, 101-107.).

\section{Divulgação da Cultura}

Outro aspecto que se pode salientar do governo de Alexandre é o seu empenho em divulgar o helenismo, o modo grego de viver, em todo território conquistado por ele.

“... Já que não podemos identificar o helenismo com um determinado país ou língua, como o definiremos? Sua essência não foi geográfica ou lingüística, mas social e cultural. O helenismo foi uma forma de vida característica, corporificada numa instituição básica, a cidade-estado, e quem se aclimatassem à vida tal como vivida numa cidade-estado helênica, seria aceito como heleno não importando qual a sua origem $\mathrm{e}$ formação..." (TOYNBEE: 1963, 19)

\section{Aspectos da Propaganda}

Em uma época em que o deslocamento de um local para outro é consideravelmente difícil, os governadores lançam mão de 
artifícios para tornarem conhecidas suas conquistas. Um monumento construído fica sedimentado em apenas um lugar, não podendo chegar a todos os súditos de um rei. Por outro lado, por meio de uma moeda essas informações chegam a populações longínquas, todos podendo saber pelo que o império está passando, não tendo apenas que acreditar no que lhes é dito, mas podendo ver em suas mãos a representação do fato que lhes é contado. Em um império vasto como o de Alexandre, este aspecto não está ausente.

Esses aspectos de propaganda não são exclusivos das civilizações antigas, pois muitas sociedades modernas utilizaram esse artifício para legitimar seu poder. Alguns exemplos: a ditadura de Francisco Franco (1939-1975) na Espanha, nas moedas de prata (100 pesetas), comemorando o aniversário do seu governo; ou nas moedas do presidente Artur Bernardes (1922-1926), de 1000 reis, nas quais uma figura feminina com os seios a mostra (representando a república e a liberdade) com uma cornucópia na mão (simbolizando abundância). São signos antigos usados como marketing das novas formas de governo e, de certa forma, como no caso de Francisco Franco, para legitimação de seu poder. Um dos aspectos que podemos utilizar para tal afirmação é a inscrição da referida moeda (100 pesetas): FRANCISCO FRANCO CAUDILHO DE LA ESPAÑA PELA GRACIA DE DÍOS, artifício utilizado diversas 
vezes nas sociedades antigas, aqui representando que o ditador tinha a "benção" de Deus em seu governo.

O trabalho com imagens não é novo, porém no Brasil sempre ficou relegado a um plano secundário. Lucien Febvre em sua obra Combates pela História amplia a noção de documento, destacando outras fontes tão ou mais importantes que as textuais:

\begin{abstract}
“... A história faz-se com documentos escritos sem duvida. Quando eles existem. Mas ela pode fazer-se, ela deve fazer-se sem documentos escritos, se os não houver. Com tudo o que o engenho do historiador pode permitir-lhe utilizar para fabricar o seu mel, à falta de flores habituais. Portanto, com palavras. Com signos. Com paisagens e telhas. Com formas de cultivo e ervas daninhas. Com eclipses da lua e canga de bois. Com exames de pedra por geólogos e analises de espadas de metal por químicos. Numa palavra, com tudo aquilo que pertence ao homem, depende do homem, exprime o homem, significa a presença, a atividade, os gostos e as maneiras de ser do homem..." (FEBVRE: 1985, 249).
\end{abstract}

As moedas, não apenas são instrumentos importantes para estabelecer a datação de documentos e eventos que chegaram até nós sem seu contexto original, mas são também de grande valia na nossa compreensão das imagens que contêm.

Com freqüência, o tipo monetário de reverso, vulgarmente conhecido como cara, nos mostra determinada representação. Ainda que o seu significado, indicado pela legenda que acompanha e pelo 
tipo do anverso (coroa), possa aparecer como uma interpretação original em relação ao modelo, muitas vezes tipos monetários e modelos têm o mesmo sentido.

Nesse caso, a numismática conserva um fragmento da história do homem e, segundo Frère "[...] se coloca hoje como uma disciplina cientifica através da sociedade [...] É uma ciência que tira da aridez do seu estudo grandes subsídios históricos." (FRÈRE: 1984, 11).

\section{Considerações Finais}

Este projeto envolve um grande numero de objetos, em torno do núcleo: o papel dos símbolos numismáticos como uma forma de legitimação de poder, no contexto da política e economia, durante o governo de Alexandre, o Grande (336 - 323 a.C. - reinando por 13 anos), que influenciou diretamente tanto o Mundo Antigo, quanto os dias atuais. Através deste diálogo, procuraremos dar conta das interações políticas que se processam entre os governantes macedônicos e seus herdeiros.

Esses signos mantêm com seu objeto uma relação causal de contiguidade física natural. Como exemplo, podemos citar as letras ou símbolos gregos localizados no campo das moedas. Eles indicam que as amoedações foram realizadas por casas monetárias de origem 
ou influência cultural grega. Realizando uma comparação com o exergo (localizado no reverso), comprovamos esta relação. Greenwell no século XIX já defendia a posição importante das cidades gregas, principalmente de Cyzicus, como centros de cunhagem (GREENWELL: 1887, 9).

Como principal objeto desse estudo, temos a moeda, valendo salientar suas principais características, no anverso e reverso. $\mathrm{O}$ anverso é a parte hierarquicamente mais importante, pois nele é encontrado o busto de quem ordenou sua cunhagem, juntamente com o título (FUNARI e CARLAN: 2007, 54). No reverso, está o exergo ( a linha de terra), em que podemos identificar o ano e local de cunhagem; junto a esse, há uma legenda ou inscrição e uma simbologia ou representação, que poderiam identificar, para os analfabetos, diversas realizações dos seus governantes.

Chevitarese, em seu artigo "Amuletos, Salomão e Cultura Helenística", afirma que a imagem de cavaleiro armado, submetendo o inimigo caído, caracterizava um símbolo natural de Vitória, constituindo um esquema iconográfico por demais conhecido na cultura helênica ou que estavam em contato com ela (CHEVITARESE: 2003, 117-135.). 
Alguns dos objetivos que temos, ao longo desse projeto, são: catalogar, com registros fotográficos, as moedas de Alexandre, o Grande, para futura publicação; contextualizar o papel dele e a sua influencia no mundo antigo; e estabelecer como a cultura helenística influenciou as sociedades vindouras (Roma, a nossa, e a própria Grécia, berço da civilização ocidental). Espera-se assim estabelecer, com base em uma nova perspectiva, o papel político e o poder nas sociedades antigas e enriquecer a área do estudo sobre o mundo antigo no âmbito nacional.

A pesquisa e catalogação dessa documentação material do mundo antigo que está conservada no acervo brasileiro é muito importante, pois amplia o campo de estudo sobre essa parte da história que ainda é pouco estudada.

\section{Agradecimentos}

Agradeço aqui ao espaço proporcionado pela Universidade Federal do Paraná e a Prof ${ }^{\mathrm{a}}$ Renata Garrafoni pela oportunidade de trocarmos ideias, e a possibilidade de mostrar o meu trabalho que ainda se encontra no início. Agradeço também a FAPEMIG e a Universidade Federal de Alfenas por ajudar no acontecimento dessa pesquisa, ao meu orientador Prof. Dr. Claudio Umpierre Carlan por 
me ajudar a desenvolver essas ideias e aos meus pais, que pela sua influência me levou ao mundo da História.

\section{Referências Bibliográficas:}

Fontes Impressas

BEJARANO, Virgilio. Hispania Antigua según Ponponio Mela, Plinio el Viejo y Claudio Ptolomeo. Barcelona: Instituto de Arqueología y Prehistoria, 1987.

Plutarco. Vidas Paralelas (Alexandre e César). Tradução de Helio Vega. São Paulo: Editora Escala.

\section{Catálogos e Dicionários}

BOWDER, Diana. Quem foi quem na Grécia Antiga. Tradução de Maristela Ribeiro de Almeida Marcondes. São Paulo: Art Editora S.A. Phaidon Press Limited, 1982.

CHEVALIER, Jean. GHEERBRANT, Alain. Dicionário de Símbolos. 23 ${ }^{\mathrm{a}}$ Ed. Tradução: Vera Costa e Silva, Raul de Sá Barbosa, Ângela Melin, Lucia Melin. Rio de Janeiro: Editora José Olympio. 2009.

COSTA, Ney Chrysostomo da. Dicionário de Numismática. Porto Alegre; Livraria Sulina Editora, 1979. 
FUNARI, Pedro Paulo Abreu. CARLAN, Cláudio Umpierre. Arqueologia Clássica e Numismática. Textos didáticos $\mathrm{n}^{\circ} 62$. Campinas: UNICAMP/ IFHC, 2007.

GREIMAS, Algirdas J. e COURTES, Joseph. Dicionário de Semiótica. Tradução de Alceu D. Lima, Diana L. P. de Barros, Eduardo P. Cañizal, Edward Lopes, Ignácio A. Silva, Maria Jose C. Sembra, Tieko Y. Miyasaki. São Paulo: Editora Labor, 1979 DICCIONARIO DEL MUNDO CLÁSSICO. Bajo la direccíon del Rvdo. P. Ignacio Errandonea. Tomo I-II. Madrid: Editorial Labor, 1954.

\section{Bibliografia Geral}

CHEVITARESE, André. Amuletos, Salomão e Cultura Helenística. Revista Fragmentos de Cultura, n 13. Goiás: PUC, 2003 FEBVRE, Lucien. Combates pela História. $2^{\mathrm{a}}$ Ed. Tradução de Leonor Marinho Simões e Gisela Moniz. Lisboa: Editora Presença Ltda, 1985

FRÈRE, Hubert. Numismática. Uma introdução aos métodos e a classificação. Tradução e adaptação de Alain Costelhes e Maria Beatriz Florenzano. São Paulo: Sociedade Numismática Brasileira. 1984.

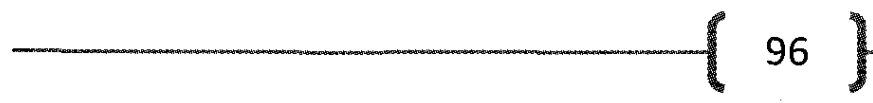


FUNARI, Pedro Paulo Abreu. Grécia e Roma: vida publica e vida privada. Cultura, pensamento e mitologia, amor e sexualidade. $2^{a}$ Ed. São Paulo: Contexto, 2002.

GREENWELL, Willian, The Electrum Coinage of Cyzicus. London: Rollin and Feuardent. 1980

SARIAN, H., Da filologia à iconografia. A permanência do arcaico nas imagens tríplices de Hécate. Clássica (São Paulo), São Paulo, v. 13/14, p. 101-107, 2001.

TOYNBEE, Arnold J. Helenismo Historia de uma civilização. Tradução de Waltensir Dutra. Rio de Janeiro: Zahar Editores. 1963. ZAMA, Cesar. Os três grandes capitães da antiguidade. Alexandre. $4^{\mathrm{a}}$ edição. Rio de Janeiro: Biblioteca do Exército Editora, 1987. 